\title{
MARTÉ SÁNCHEZ Y JERÓNIMO RÍOS Breve historia de Sendero Luminoso
}

Madrid, 2018: Revuelta Editores/Catarata. DOI: http://dx.doi.org/10.15381/is.v22i40.15936

La senderología como tradición académica tiene de ciencia positiva y de esoterismo a la vez. Sobre lo primero es necesario acumular datos sobre un tema complejo en que no sólo se impone el afán de la veracidad, sino que como ocurre con las guerras, estos tienen que emerger sólidos sin hacernos daño y donde muchas veces el silencio, el olvido, las medias verdades y las leyendas creadas enrarecen la madeja de la información. Sobre el segundo, es la invocación para que una vez desbrozados, estos datos sean incorporados a marcos significados que son las teorías o los modelos explicativos, y que estos, no colmen de ira a las partes. Este equilibrio y aparente neutralidad, cede muchas veces a la fuerza que el Estado o los grupos involucrados hacen sentir su rigor.

Como en la película española Las bicicletas son para el verano (1984), donde no hay paz, existe la victoria, los derrotados muerden la humillación y los vencedores se apropian del escenario que queda del conflicto y que muchas veces, impide sellar las heridas. En ese sentido, el libro de Sánchez/Ríos se torna imprescindible para todo aquel que (lejos de la información especializada) desee tener una idea general del surgimiento de Sendero Luminoso (SL) y los inicios de lo que denominaron la «lucha armada». En ese ejercicio los autores también se interrogan sobre el destino de un país y el de sus instituciones que parecen hoy, estar en una crisis acentuada.

De lectura ágil y con una prosa amena, el libro tiene cinco capítulos. Los dos primeros nos informan del surgimiento de SL vinculado al conflicto sino-soviético de mediados del siglo xx. Aquí llama la atención la compulsiva división del partido que fundara Mariátegui. Esto puede ser explicado por la sobreactuación en la discusión ideológica de la izquierda peruana para revertir su escasa vinculación con bases obreras y campesinas y también, por su origen universitario. En el segundo capítulo toca con datos valiosos, el inicio y desarrollo de la lucha armada de los años 80 y 90 del mismo siglo.

Aquí, queremos discutir brevemente las fuentes del cual se nutren los autores. Los textos de Carlos Iván Degregori (CID), de la Comisión de la Verdad (CVR) y la tesis universitaria de Manuel Granados (1981) sirven de manantial autorizado. Creemos que esto pudo haberse afinado. De los textos de CID sabemos que muchos de ellos se basan en información de segundo orden del cual, muchas son versiones que circulaban por Ayacucho en aquellos años. Quizás esa fue la razón por la que sus críticos más enraizados en la región, lo llamarían «narrador de cuentos», atributo que el mismo reconoce con cierta ironía en sus memorias (2015). También hubiese sido importante consultar la valiosa información contenida en la tesis doctoral del sociólogo sanmarquino Aracelio Castillo, sobre el movimiento estudiantil de Huanta de 1969. La figura de Saturnino Paredes (al que CID considera carente en absoluto de lustre muy a tono con el típico desprecio provinciano) casi marginal en el texto, pudo ofrecer circunstancias detalladas sobre las luchas internas en Bandera Roja y que de ellas exhausta, emergerá SL. No olvidemos que un libro suyo como fue Las clases sociales en el campo (1976), sirvió como una plantilla para muchas tesis de la Universidad de Huamanga, que trataban sobre la caracterización de la sociedad rural y que al final de cuentas, esos mismos postulados fueron compartidos por muchos grupos maoístas, incluido SL.

También útil, se pudo revisar la tesis de grado de Ranulfo Cavero (1978) quien caracteriza al Perú como una sociedad semifeudal y semi-colonial. Todo esto, más la folletería y el material escrito de los congresos, conferencias y reuniones de SL, pudieron ofrecerse como fuentes empíricas invaluables.

El tercer capítulo nutrido y veraz, se desliza por los momentos más críticos de la violencia política que puso en jaque el país. El inicio de la lucha armada (ILA) en el departamento de Ayacucho y que luego como una fuente irradiada se expandirá por gran parte del territorio, provocando en 1983 la intervención de las Fuerzas Armadas que colocó a los campesinos entre dos fuegos. Aunque cabría mencionar que cuando los autores tratan de explicar el avance y el crecimiento de SL ensayan 4 razones coyunturales que se ofrecen como causalidades (página 84), aunque para nosotros el fundamento genérico sería el hecho de que sendero crece y se desarrolla por la situación de subdesarrollo del país. Esto que se denominan causas estructurales, se ofrecen como pro- 
blemáticos y que al igual que la denominación del conflicto (¿Interno? ¿Guerra civil? ¿'Terrorismo?), tiene que ver con los intereses en pugna y con la lucha por la memoria. Es decir, regresamos al esoterismo.

La violencia estructural ha sido negada por la derecha política por considerarla justificadora del «terrorismo» y también porque los absuelve de su responsabilidad histórica al no poder construir un país. La superposición de planos de subdesarrollo que está implícita en su definición, será el almácigo donde germinará un movimiento tan letal y que también explica la respuesta del Estado. En ello, el texto no ahorra tinta en exponer los casos de masacres más emblemáticos sucedidos en los 80: Lucanamrca, Accomarca, Cayara, Pucayacu, Putis o Socos, nos muestran el horror de dar una lección a las mesnadas o la represión indiscriminada de la guerra sucia.

Los dos últimos capítulos están referidos a la derrota de SL en el contexto del gobierno de Fujimori y las nuevas facciones que ha alcanzado hoy, el movimiento maoísta. Ambos capítulos están contenidos en una atmósfera del debilitamiento de la democracia, el fortalecimiento del autoritarismo y la impunidad de los responsables de la violación de derechos humanos. Los años 90 son complejos porque se cruzan distintas rutas: SL se distancia de su epicentro andino y se instala en Lima y se abre un nuevo frente en el Huallaga, donde imbricados con el narcotráfico, inauguran una nueva etapa de violencia y de actuación política. Por otro lado el fujimorismo al compás con la corrupción, necesitaba a través de la impunidad, garantizar la adhesión de los militares. Dicho sea de paso, ambos protagonistas de la guerra (senderistas y militares) se lumpenizarán con la economía ilegal.

Luego de la captura de Abimael Guzmán y con el retorno de la democracia es que, SL traslada su centro de gravitación hacia el VRAEM. Lugar estratégico por estar cercada por el macizo andino, por su cercanía al Brasil y Bolivia (nuevos centros de compra) y un colchón humano más complejo, compuesto por migrantes andinos prove- nientes básicamente de Junín, Ayacucho, Huancavelica, Apurímac y Cusco. Pareciese que se remedasen los escenarios originales.

Finalmente, los llamados rezagos de Sendero Rojo o Proseguir coexisten con organizaciones del trasiego cocalero en espacios encapsulados y con conflictos de baja intensidad, que convienen tanto al Estado como a aquellos. Permiten por ejemplo, que las FF.AA estén en adiestramiento constante en escenarios reales (con un balance equilibrado), que facilite los presupuestos militares cuyos usufructuarios directos son los oficiales y que instauren temor en la población urbana para legitimar -como diría Bourdieu- las «lógicas del Estado». También ha robustecido las economías regionales tanto por las transferencias para la inversión pública, como por el vigor de la economía cocalera y finalmente permite que SL (o lo que queda de ella) sobreviva, moviéndose estando quietos.

Libro imprescindible para consultas oportunas y una muestra del esfuerzo académico gestado inicialmente en la universidad pública.

\section{Bibliografía}

Castillo, A. (1972). Movimiento de junio de 1969. Lima: Tesis de Dr. en Sociología, UNMSM

CaVero, J.R. (1978). ¿Semifeudal y neocolonial o capitalista? Ayacucho: Tesis de Antropólogo, UNSCH.

Granados, M. (1985). La conducta política: un caso particular. Ayacucho: UNSCH. Tesis de Bachiller en Antropología.

Paredes, S. (1976). Las clases sociales en el campo. Lima: Tercer Mundo.

Sandoval, P. y J.C. Agüero (1985). Aprendiendo a vivir se va la vida. Conversaciones con Carlos Iván Degregori. Lima: IEP.

Rommel Plasencia Soto rplascencias@unmsm.edu.pe 